\title{
$\begin{array}{lllllllll}\text { I } & \mathrm{N} & \mathrm{S} & \mathrm{T} & \mathrm{I} & \mathrm{T} & \mathrm{U} & \mathrm{T} & \mathrm{E}\end{array}$
}

\section{Natural Decrease in America More Coffins than Cradles}

$\mathrm{B}$ irths have always exceeded deaths in the United States by a substantial margin, so little attention has been paid to specific areas where more people die than are born. Yet, in some parts of rural America, deaths have exceeded births for decades. This point was illustrated recently by a rural Kansas minister who said that he officiates at four funerals for every baptism.

This brief summarizes recent regional patterns of natural decrease in the United States. ${ }^{1}$ Natural decrease occurs when more deaths than births occur in an area in a given year. The growing incidence of natural decrease in rural America has gone largely unnoticed, yet natural decrease is no longer an isolated phenomenon occurring in a few remote corners of rural America. Last year, 24 percent of all U.S. counties experienced natural decrease. And, for the first time in U.S. history, deaths now exceed births in an entire state. Between 2000 and 2009, more people in West Virginia died than were born. And West Virginia may be a harbinger of things to come. In several other states, births now outnumber deaths by the thinnest of margins. For example, last year in Maine there were only 106 births for every 100 deaths. Overall, births exceeded deaths in Maine by just 789 according to the latest Census Bureau estimates. These margins may well become even thinner in the near future. The latest data from the National Center for Health Statistics reflect the adverse impact of the current recession on U.S. births. In all, 260,000 fewer babies were born in the twelve months ending in June of 2010 than were born in the twelve months ending in June of 2008. This represents a 6 percent decline in just two years.

\section{Once Rare Phenomenon Becoming More Widespread}

Historically, natural decrease has been unusual in the American experience. Near the end of the Great Depression, natural decrease occurred in a few counties, but it was short-lived. It occurred again in a few places during

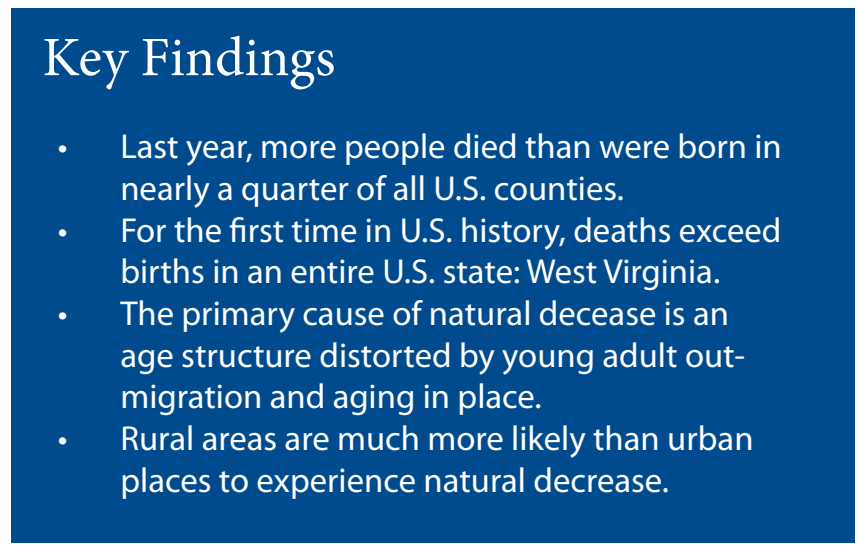

the 1950s, but natural decrease was rare during the high fertility era of the baby boom. Natural decrease became more common near the end of the 1960s, as fertility levels fell. The longitudinal pattern during the 1970s was different from the slow rise during the 1950s and 1960s. After a brief respite in 1970 and 1971, both the number of counties experiencing natural decrease in a given year and the number experiencing it for the first time rapidly rose to a peak in 1973. Natural decrease increased sharply during this period because the children of the baby boom delayed their first births and had fewer children than their mothers did. Natural decrease diminished later in the 1970s as these delayed births began to materialize. It remained at a low ebb through 1982, but then began to rise, nearly doubling by 2000 . The number of natural decrease counties peaked in 2002 at 985 before subsiding somewhat, as fertility levels rose. However, recent Census Bureau estimates of births and deaths through July of 2009 suggest the incidence of natural decrease is again rising. In all, 1,621 of the 3,141 U.S. counties (51.6 percent) experienced at least one year of natural decrease between 1950 and 2009. See Figure 1 for an illustration of the longitudinal pattern of natural decrease from 1950 through 2009. 
Figure 1. Natural Decrease in U.S. Counties, 1950 TO 2008

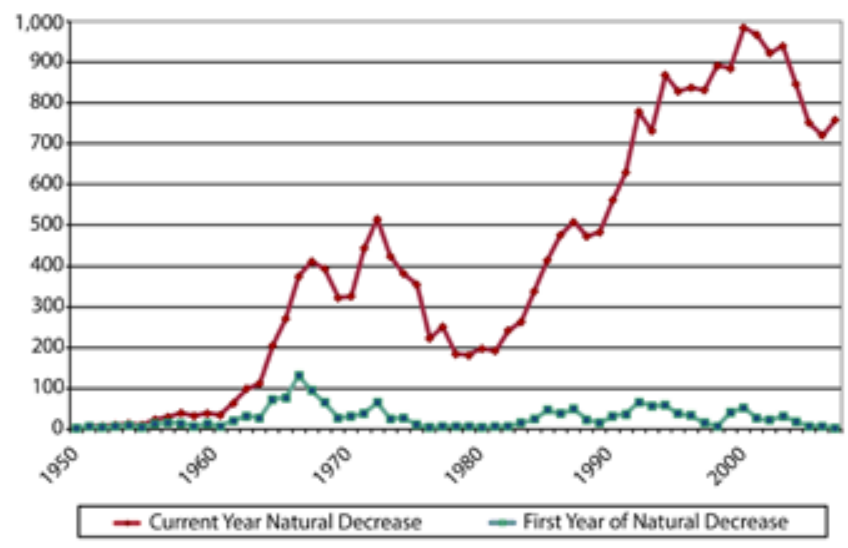

Source: National Center for Health Statistic and Federal State Cooperative Population Estimates

\section{Natural Decrease Is More Common in Rural Areas}

Natural decrease is common in rural areas; more than 90 percent of U.S. counties with episodes of natural decrease are classified as nonmetropolitan. Between 2000 and 2009, 750 nonmetropolitan counties (36 percent) had more people die in them than be born. This is up from 29 percent in the 1990s. The incidence and severity of natural decrease is influenced by proximity to metropolitan areas. Nearly 45 percent of remote rural counties-those not adjacent to a metropolitan area-had natural decrease between 2000 and 2009. In contrast, only 30 percent of rural counties adjacent to metropolitan counties experienced natural decrease.

Natural decrease is regionally concentrated. The earliest occurrences of it in the 1950s were in agricultural areas of the Great Plains, the Western and Southern Corn Belt, and East and Central Texas, as well as in the OzarkOuachita Uplands. Natural decrease also was observed early in some mining and timber-dependent rural counties of the Upper Great Lakes and in Florida counties that were among the first to receive retirement migrants (see Figure 2). Later, natural decrease spread to other rural areas of the South, New York and Pennsylvania, the Upper Great Lakes, parts of the West in the 1990s, and eventually to Indiana and Ohio.

The heavy concentrations of natural decrease counties in the Great Plains and in the Corn Belt reflect the linkage between dependence on agriculture and persistent outmigration and low fertility. Farming counties are the most likely to suffer natural decrease; nearly 50 percent experienced natural decrease between 2000 and 2009. Many agricultural counties have sustained decades of outmigration by young adults, leaving behind fewer young families of childbearing age. Natural decrease also is observed in many rural counties classified as retirement destinations by the U.S. Department of Agriculture. Retirement counties have received a substantial net inflow of older adults for many years. Older migrants push up mortality rates, while obviously contributing nothing to the number of births in counties. The retirement counties of Florida are the best examples of this phenomenon, but similar clusters exist in retirement destinations of the Upper Great Lakes, the Southeast, Ozarks, and portions of the West.

\section{Figure 2. Years of Natural Decrease, 1966 to 2009}

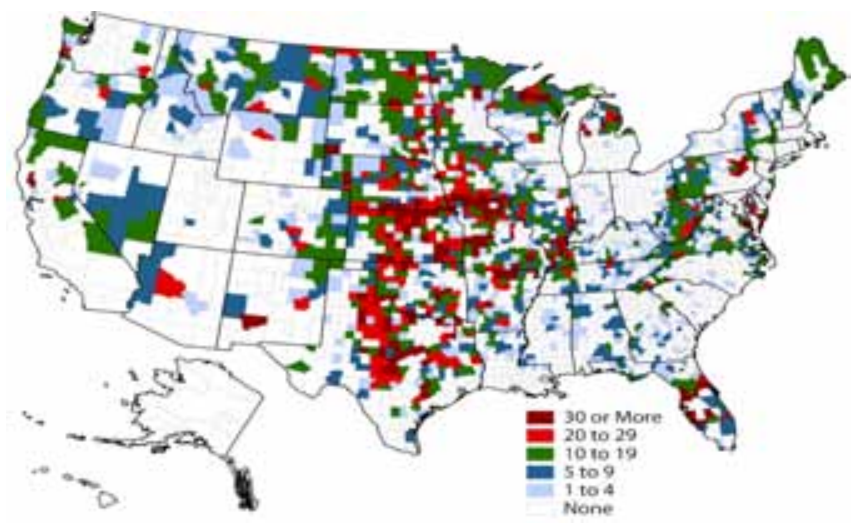

Source: Data from Census Bureau and National Center for Health Statistics

\section{What Causes Natural Decrease?}

Natural decrease is caused by two interrelated demographic factors. The most influential of these factors is a local age structure that has few young adults of child-bearing age and a large surplus of older adults at high risk of mortality. Natural decrease is also more likely when fertility levels are low because women are having relatively few children.

Areas that have both a deficit of young adults and a surplus of older adults are at the greatest risk of natural decrease. Eventually, even with fertility rates at the national average, diminishing numbers of young adults cannot produce sufficient births to offset the rising number of deaths to the larger, older cohorts. Natural decrease counties have significantly fewer 20- to 39-year-olds than the other areas (see Figure 3). In 2000, counties with extensive natural decrease average 27 percent fewer residents in their 20 s than the United States as a whole. Because this part of the population is in its prime child-bearing years and produces most of the babies, a shortfall in this age group significantly reduces the number of local births.

Natural decrease counties are also populated by a disproportionate share of older adults. This surplus is greatest among those over the age of 70 . Counties with overall natural decrease between 1990 and 2000 had 59 percent 
Figure 3. Age Structure Difference between Natural DeCrease AND ALl U.S. Counties, 1960 TO 2000

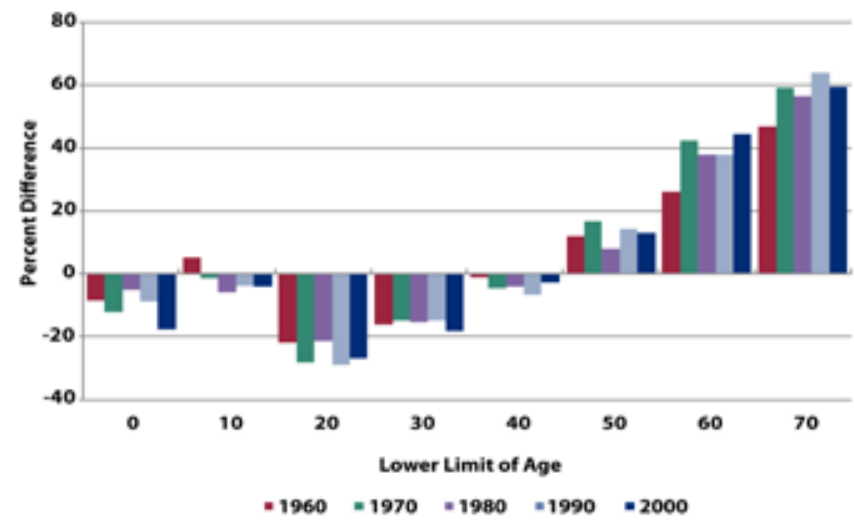

Source: U.S. Census 1950 to 2000

more people over the age of 70 than the United States as a whole in 2000. Because age-specific mortality rates are much higher for older adults, their disproportionate concentration in these counties accelerates natural decrease by increasing the number of deaths.

Prolonged age-specific migration patterns produced the age structure shifts evident in rural natural decrease areas. For decades, migration drained young adults from these areas, while the older population remained (or grew through migration). The exodus of young adults and retention of older adults is not unique to natural decrease areas; in fact, it is common in much of nonmetropolitan America. What differs is its magnitude. In natural decrease areas, the outflow of young adults (20 to 29 ) was more substantial. Counties that experienced overall natural decrease between 1990 and 2000 lost hundreds of thousands of 20- to 29-year-olds between the 1950s and the 1990s (see Figure 4). The demographic impact of this young adult out-migration is magnified by the aging in place and by an influx of older migrants in some areas. Thus, for several generations the older population has grown while the young left.

\section{Figure 4. Net Migration in Natural Decrease}

COUNTIES, 1950 TO 2000

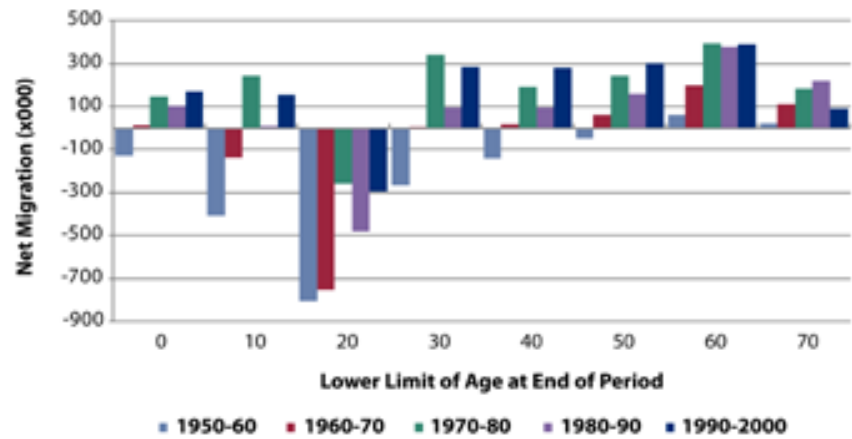

Source: Johnson, et.al. 2005. Demography 44(4): 791-812
Low fertility levels also impact the incidence of natural decrease and may be of growing importance today. However, the relationship between natural decrease and fertility is complex and its overall impact is modest. The high fertility of the baby boom era postponed the onset of natural decrease in many counties, while the rapid fertility decline in the early 1970s contributed to its rising incidence at the time. The ebb and flow of natural decrease roughly approximates nationwide trends in fertility from 1950 to 1980. However, natural decrease rose sharply after 1980 despite an upward trajectory in births in the nation as a whole (data not shown).

Why have births diminished so rapidly in nonmetropoli$\tan$ natural decrease areas over the past several decades? It is not because women in such areas are having fewer children than their counterparts elsewhere in the United States. Although the gap between fertility levels in natural decrease counties and the United States have diminished in recent decades, such counties still had total fertility rates near the national average in 2000. However, a general decline in nonmetropolitan age-specific fertility rates contributed to the diminished number of births in natural decrease areas after 1980. Rural women have historically had higher birth rates than urban women, but the rates have been converging for some time and, by 1990, the overall fertility rates of urban and rural women were virtually equivalent. So, both temporal variations and normative changes in family size contributed to the changing incidence of natural decrease. For example, while the baby boom and higher fertility among rural women delayed the onset of natural decrease in many rural counties, the tendency of the baby boomers themselves to delay having children coupled with converging rural-urban fertility levels sharply increased the incidence of natural decrease more recently.

\section{The Implications of Natural Decrease}

Natural decrease is the ultimate demographic consequence of dwindling numbers of young adults and growing older populations, but it has implications that reach far beyond demography to institutions that are the bedrock of communities. The viability of local schools becomes precarious as the student and parent populations diminish. With fewer births and children, the delivery of obstetric and pediatric services by local hospitals and physicians also becomes increasingly problematic-leaving the few remaining prospective parents to travel to distant hospitals and physicians for prenatal and well-baby care that reduces the risks to vulnerable mothers and children. The provision of daycare and family services is also difficult when families with children are few and scattered. And, the needs of families and children may get less attention in the political arena than those of the growing senior population. 
Firms planning to open or expand facilities may be reluctant to consider areas with a declining young adult population. Staffing voluntary organizations is challenging when fewer young and middle aged adults reside in the area. Who will staff volunteer fire departments and emergency medical services when there are few working age adults and those that remain commute long distances to jobs? The tax base is also likely to stagnate in communities with declining working age population. And, with protracted population decline, the political clout of natural decrease communities is diminishing.

\section{Will Natural Decrease Continue?}

The recent rise in natural decrease may be a harbinger of future trends. Once natural decrease begins in a county, it is likely to reoccur. Nearly 90 percent of the counties that have experienced natural decrease once experience reoccurrences of it. The demographic forces stimulating natural decrease also increase the likelihood of it in the future. The cohorts reaching retirement age in the last decade and a half were small because they were born during the low fertility era of the 1930s and early 1940s. Now, that the large baby boom era cohorts are poised for retirement, the number of older adults at high risk of mortality will grow dramatically over the next several decades. The recent decline in fertility associated with the Great Recession also increases the likelihood of more natural decrease in the near term.

Predicting the demographic future is always perilous. Not all natural decrease areas face a bleak future. Although natural decrease will likely continue in many areas and appear for the first time in others, this is not a demographic certainty everywhere given the recent influx of immigrants into some regions of rural and urban America. New immigration has brought significant increases in the number of Hispanic births, which are impacting natural increase. Hispanics represent only 16.4 percent of the U.S. population, but they produced 26 percent of all births last year. This influx of immigrants and new minority groups to America is having a profound impact on natural increase and the age structure of the U.S. population. ${ }^{2}$

In sum, the ebbs and flows of natural decrease over the last half century have gone largely unnoticed. Yet, the pronounced spatial clustering of natural decrease coupled with its protracted incidence in some rural areas underscores the significant implication it has for the future of these regions. With few young adults and a growing older population, the future viability of many natural decrease areas is not encouraging. Demography is not destiny, but one ignores it at their peril. Economic development, an influx of minorities, high levels of civic engagement and community cohesion have broken the downward spiral of natural decrease in some areas, but many remain at risk.

\section{Examples of Counties with Sustained Natural Decrease}

Over time, the effect of age structure distortions resulting from the protracted outflow of young adults from an area combined with declining fertility can have a substantial impact on an area's population. Two countiesRepublic County in Kansas and Ontonagon County in Michigan-illustrate the demographic processes that cause natural decrease and suggest the significant implications that prolonged natural decrease can have for rural areas.

Republic County, a farm county in North Central Kansas, experienced decades of young adult outmigration leaving it with 27.4 percent of its population over 65 (the United States has 13 percent over 65) and only 10.4 percent of its population between 20 to 34 (the U.S. statistic is 20.4 percent). As a result, Republic County experienced natural decrease in each of the last 42 years. It had roughly twice as many deaths as births between 2000 and 2009 ( 812 deaths and 437 births). Such natural decrease combined with protracted outmigration mean that only 4,960 people lived in Republic County in 2010, compared to 17,447 in 1910 .

The story is similar in Ontonagon County located in Michigan's western Upper Peninsula where mining and timber were once the dominate industries. For decades, young adults left for jobs in the booming metropolitan areas of the Midwest. As a result, some 21.8 percent of the county's population is 65 or more, and only 11 percent is between 20 and 24 . Here there were just 44 births for every 100 deaths between 2000 and 2009 (1,014 deaths and 448 births). Like Republic County, the population of Ontonagon County has diminished from a peak of 12,428 in 1920 to 6,780 in 2010 . 


\section{E N D N O TES}

1. This report summarizes and updates my article, "The Continuing Incidence of Natural Decrease in American Counties," published in Rural Sociology in March of 2011. For information about the data and methods used in this report, reference the article. My Rural Sociology article is one of several published to commemorate the work of Calvin L. Beale, Senior Demographer at the Economic Research Service of the USDA. With more than fifty years of expertise gleaned from pouring over data and his travels to nearly every corner of rural America, Mr. Beale was considered the Dean of Rural Demography, and he was respected and honored by the demographic and rural research community.

2. For more information about the influence of minorities on U.S. demographic trends, see the following recent Carsey publications by Kenneth Johnson and Daniel Lichter: "The Changing Faces of America's Children and Youth" (at www. carseyinstitute.unh.edu/CarseySearch/search.php?id=50) and "Population Growth in New Hispanic Destinations" (at www.carseyinstitute.unh.edu/CarseySearch/search. php?id=19).
A B OUT THE AUTHOR

Kenneth M. Johnson is senior demographer at the Carsey Institute and professor of sociology at the University of New Hampshire (ken.johnson@unh.edu).

\section{A C K N O W L E D G M E N T S}

Thanks to Allison Churilla for research assistance, Barbara Cook for GIS support, and Curt Grimm, Laurel Lloyd Earnshaw, Beth Mattingly, and Amy Sterndale for their comments and suggestions. 


\section{ANIVERSITY}

\section{CARSEY}

Building knowledge for families and communities

The Carsey Institute conducts policy research on vulnerable children, youth, and families and on sustainable community development. We give policy makers and practitioners timely, independent resources to effect change in their communities.

This work was supported by the Annie E. Casey Foundation, the W. K. Kellogg Foundation, the Ford Foundation, and by the Northern Research Station of the U.S. Forest Service and the Economic Research Service of the USDA.

Huddleston Hall

73 Main Street

Durham, NH 03824

$(603) 862-2821$ 